\title{
One visit endodontic on asymtomatic mummificated mandibular molar
}

\author{
Sholeh Ardjanggi ${ }^{1}$, Eric Priyo Prasetyo ${ }^{2}$, Tamara Yuanita ${ }^{2}$, Dian Agustin Wahjuningrum ${ }^{2}$ \\ ${ }^{1}$ Conservative Dentistry Resident, Faculty of Dental Medicine, Universitas Airlangga, Surabaya, Indonesia \\ ${ }^{2}$ Department Conservative Dentistry,Faculty of Dental Medicine, Universitas Airlangga, Surabaya, Indonesia.
}

\begin{abstract}
Background: The main goal of root canal treatment is the prevention or treatment of apical periodontitis, which leads to the preservation of natural teeth. Traditionally, root canal treatment is carried out in a number of visits, using extra disinfecting agents in addition to irrigant used during cleaning and shaping procedures that primarily aim to reduce or eliminate microorganisms and their byproducts. from the root canal system before it is obtained. Recent advances in Endodontic technology, attracting dental experts and endodontists to perform root canal treatment in one visit. Numerous studies evaluate the effectiveness of single-versus multiple-appointment root canal treatment have been published, which reported no significant differences in effectiveness (healing rates) between these two treatment regimens.Purpose: preservation of the integrity of the molar teeth that have symptomatic complaints by taking proper care with a short visit time. Case: A 21-year-old woman presents with concern in her lower left tooth, the patient tells that the tooth had been treated before at the dentist when she was a child. On clinical examination there is a composite restoration in occlusal tooth \# 36, non vital teeth. On periapical radiology there are radiopaque on pulp chamber and a diffuse radiolucent area in the apical area of tooth \# 36, then the diagnosis then determined Previously initiated therapy with asymptomatic apical periodontitis. Case Management: Tooth \# 36 treated with one visit root canal treatment, Treatment is continued with fiber post installation and crown, patients no longer complain of pain after treatment. Teeth function normally again. Conclusion: One visit root canal treatment can successfully eliminate patient complaints and restore tooth function.
\end{abstract}

Keywords: one visit endodontic; previously initiated therapy; asymtomatic; mummificated; irrigation

Correspondence: Dian Agustin Wahjuningrum, Department of Conservative Dentistry, Faculty of Dental Medicine, Universitas Airlangga. Jl. Prof. Dr. Moestopo 47 Surabaya 60132, Indonesia. Email: dian-agustin-w@fkg.unair.ac.id

\section{INTRODUCTION}

American Association of Endodontists divides pulpotomy/ pulp amputation into vital amputation and mortal/ devitalization/ mummification amputation. Mummification is the removal of a devitalized pulpal tissue inside the pulp. The pulp tissue inside the root canal was left in a sterile condition and mummified by mummification medicament. Mummification used as an emergency procedure in many developing countries to decrease pain until the advanced endodontic treatment can be done. ${ }^{1}$

Previously initiated therapy is a clinical diagnostic category indicating that the tooth has been previously treated by partial endodontic therapy such as pulpotomy or pulpectomy. Depending on the level of therapy, the tooth may or may not respond to pulp testing modalities. Symptomatic apical periodontitis is inflammation and destruction of the apical periodontium that is of pulpal origin. It appears as an apical radiolucency and does not present clinical symptoms ${ }^{1}$

Single-appointment root canal therapy has become a common practice. When questioned, however, most general dentists reply that they reserve one-appointment treatment for vital pulp cases and immediate periapical surgery cases. In 1982 , only $12.8 \%$ of dentists queried thought that necrotic teeth would be successfully treated in one appointment. On the other hand, endodontists have been treating patients in one-appointment visits for some time. At one time, $86 \%$ of the directors of postgraduate endodontic programs, when surveyed, reported that nonsurgical one-visit treatment was part of their program. Today it is universal. ${ }^{2} \mathrm{~A}$ number of studies have determined that less postoperative pain results from a single-visit approach to endodontics than a multi-visit course of treatment. ${ }^{2}$ Advantages such as immediate familiarity with the internal anatomy, canal shape, and contour facilitates obturation, no risk of bacterial leakage beyond a temporary coronal seal between appointments, reduction of clinic time, patient convenience - no additional appointment or travel and low cost. ${ }^{2}$

Wolch said it best: "In the treatment of any disease, a cure can only be affected if the cause is removed. Since endodontic diseases originate from an infected or affected pulp, it is axiomatic that the root canal must be 
thoroughly and carefully debrided and obturated" (personal communication, 1983). ${ }^{3}$

\section{CASE}

A 21-year-old woman presents with concern in her lower left tooth, the patient tells that the tooth had been treated before at the dentist when she was a child. On clinical examination there is a composite restoration in occlusal tooth \# 36, non vital teeth. On periapical radiology there are radiopaque on pulp chamber and a diffuse radiolucent area in the apical area of tooth \# 36, then the diagnosis then determined (Figure 1). Previously initiated therapy with asymptomatic apical periodontitis.

\section{CASE MANAGEMENT}

The work is done by installing rubber dam insulation before starting the cleaning. Then the work length was measured by the apex locator and confirmed using periapical radiography. MB : 21mm, ML: 21mm DB: 22mm, DL: $22 \mathrm{~mm}$. Root canal preparation then proceed with crown down presureless (CDP) technique (Figure 2).

The root canal preparation is done using Protaper Next to X2 files on all root canals, after h a try-in photo
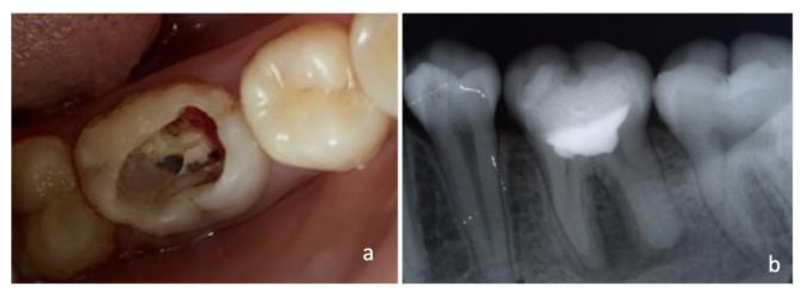

Figure 1. a.clinical view b. periapical radiograph on 36 .

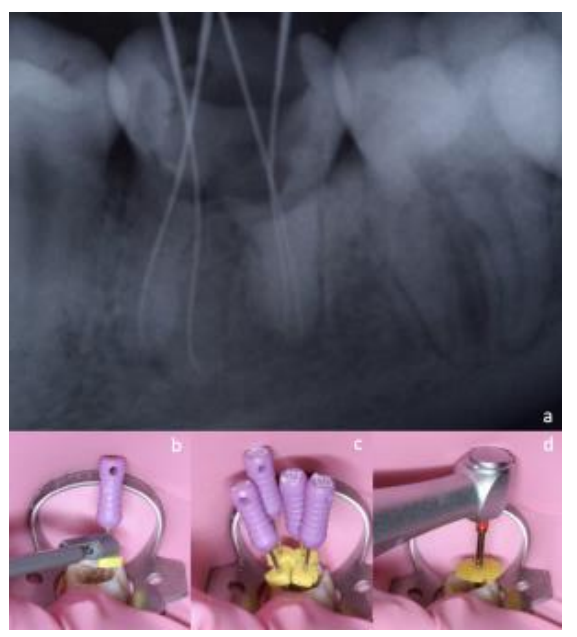

Figure 2. a. periapical radiograph working length determination b. working length measured with apex locator. c. four canal with each working length files. d. clinical view of root canal preparation. confirmation of filling is done using guttappercha size X2, root canal obturated with single cone technique. Then periapical photographs were obtained after obturation (Figure 3).

Post preparation is done a week later on mesiolingual and distolingual roots, then radiograph confirms the placement of the fiber post by periapical radiography. Fiber posts are cemented using GIC then proceed with core build up (Figure 4). Crown preparation was carried out on tooth \#36 with a shoulder ending that would later be fitted with a porcelain fused to metal crown. 3 days later the temporary crown was removed and the PFM was permanently inserted using GIC. On control 7 days and 30 days later there were no complaints reported by the patient, teeth can function normally again.

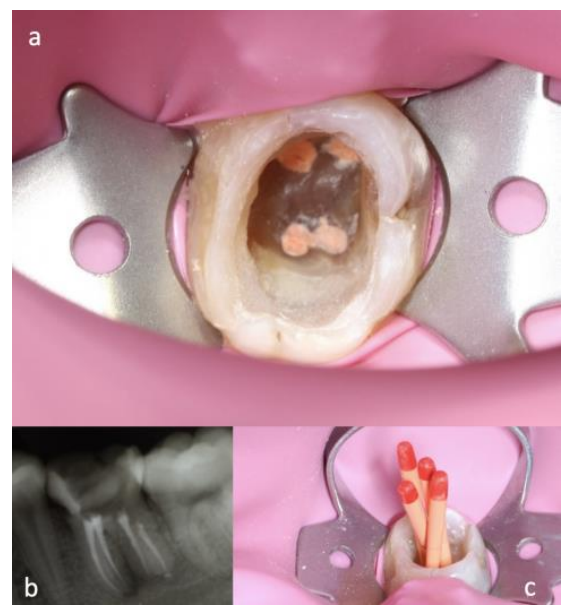

Figure 3. a. occlusal view of root canal after obturation b. periapical radiograph view of root canal after obturation c. guttap percha trial confirmation for each canal.

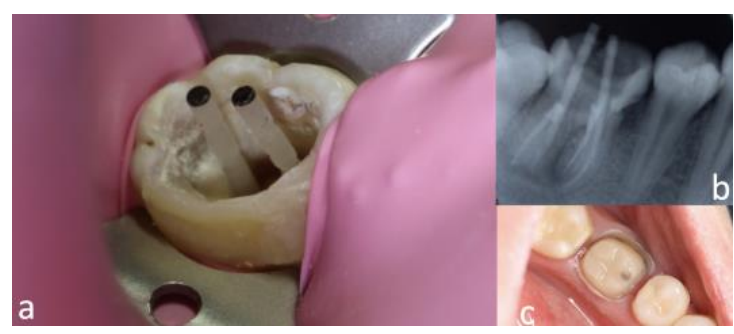

Figure 4. a. fiber post trial clinical view b. fiber post periapical radiograph placement confirmation. c. 36 after fiber post cementation and build up.
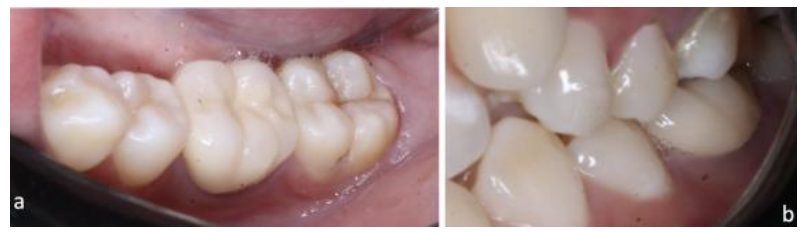

Figure 5. a. occlusal view after crown sementation b. crown in relation in occlusion. 
Tooth \# 36 successfully treated with one visit root canal treatment, patients no longer have a complain after treatment. Teeth function normally again (Figure 5). One visit root canal treatment can successfully eliminate patient complaints and restore tooth function

Mummification used as an emergency procedure in many developing countries to decrease pain until the advanced endodontic treatment can be done mummification used as an emergency procedure in many developing countries to decrease pain until the advanced endodontic treatment can be done. Mummification used as an emergency procedure in many developing countries to decrease pain until the advanced endodontic treatment can be done.

\section{DISCUSSION}

Single-appointment root canal therapy has become a common practice. When questioned, however, most general dentists reply that they reserve one-appointment treatment for vital pulp cases and immediate periapical surgery cases. In 1982 , only $12.8 \%$ of dentists queried thought that necrotic teeth would be successfully treated in one appointment. ${ }^{2,3}$ The main goal of root canal treatment is the prevention or treatment of apical periodontitis, which leads to the preservation of natural teeth. The presence of bacteria in the root canal system results in the development of periapical lesions. Traditionally, root canal treatment is carried out in a number of visits, using extra disinfecting agents (intracanal dressing) in addition to irrigant used during cleaning and shaping procedures that primarily aim to reduce or eliminate microorganisms and their byproducts. from the root canal system before it is obtained..$^{4-7}$

Studies have shown that instrumentation and irrigation of the root canal system substantially reduce the number of cultivable microorganisms but rarely lead to a total eradication. Minute differences in periapical healing were observed among individuals undergoing single visit and multiple visit root canal treatment and bacterial growth at the second appointment had a significant negative impact on healing of the periapical lesion. In addition to this, the clinical efficacy of sodium hypochlorite irrigation in the control of root canal infection is much more than the effectiveness of inter-appointment calcium hydroxide dressing, in disinfecting the root canal system and treatment outcome, indicating the need to develop more efficient inter-appointment dressings. ${ }^{4,8-11}$
The single-visit root canal treatment is safe in terms of endodontic flare-ups as far as results of this study are concerned. It is safer in both vital and non-vital teeth, and even teeth with periapical pathosis. A thorough understanding of the basic endodontic principles is important in considering each case on an individual basis before making a decision as to whether or not it can be completed in one visit. ${ }^{4-8}$ In conclusion, One visit root canal treatment can successfully eliminate patient complaints and restore tooth function

\section{REFERENCES}

1. Garg, Nisha, and Amit Garg. 2014. Textbook of endodontics.

2. Ingle, John Ide, Leif K. Bakland, J. Craig Baumgartner, and John Ide Ingle. 2008. Ingle's endodontics 6. Hamilton, Ontario: BC Decker

3. Hargreaves, K. M., Cohen, S., \& Berman, L. H. (2016). Cohen's pathways of the pulp. St. Louis, Mo: Mosby Elsevier.

4. Dennis, Cut Nurliza (2017) Single Visit Endodontic in the Management of Symptomatic Irreversible Pulpitis and Pulp Necrosis with Apical Periodontitis: Report of Two Cases. Int J Dentistry Oral Sci. 4(2), 418-421

5. Sathorn C, Parashos P, Messer HH (2005) Effectiveness of singleversus multiple-visit endodontic treatment of teeth with apical periodontitis: a sys

6. tematic review and meta-analysis. Int Endod J. 38(6): 34755 Peters LB, Wesselink PR (2002) Periapical healing of endodontically treated teeth in one and two visits obturated in the presence or absence of detectable microorganisms. Int Endod J. 35(8): 660-7.

7. Field JW, Gutmann JL, Solomon ES, Raakusin H (2004) A clinical radiographic retrospective assessment of the success rate of single-visit root canal treatment. Int Endod J. 37(1): $70-82$.

8. Nair PNR, Henry S, Cano V, Vera J (2005) Microbial status of apical root canal system of human mandibular first molars with primary apical periodontitis after 'one-visit' endodontic treatment. Oral Surg Oral Med Oral Pathol Oral Endod. 99(2): 231-52.

9. Pekrun RB (1986) The incidence of failure following singlevisit endodontic therapy. J Endod. 12(2): 68-72.

10. Peters LB, Wesselink PR, Moorer WR (1995) The fate and the role of bacteria left in root dentinal tubules. Int Endod J. 28(2): 95-9.

11. SjögrenU, FigdorD, PersonS, SundqvistG (1997) Influence of infection at the time of the root filling on the outcome of endodontic treatment of teeth with apical periodontitis. Int Endod J. 30(5): 297-306. 